\title{
The Use of the Amplatz Sheath in Percutaneous Nephrolithotomy: Does Amplatz Sheath Size Matter?
}

\author{
Ayhan Karaköse Özgu Aydogdu Yusuf Z. Atesci \\ Izmir University School of Medicine, Department of Urology, Karsiyaka, Izmir,Turkey
}

\section{Key Words}

Percutaneous nephrolithotomy • Nephrostomy •

Amplatz sheath $\cdot$ Treatment outcome

\begin{abstract}
Objectives: To evaluate the effect of Amplatz sheath size used in percutaneous nephrolithotomy (PCNL) on postoperative outcome, bleeding, and renal impairment rates. Materials and Methods: One-hundred and ten patients who underwent uneventful percutaneous nephrolithotomy between November 2011 and October 2012 were included in the study. The patients were divided into 5 groups based on Amplatz sheath size $(22,24,26,28$ and $30 \mathrm{Fr}$ ). Groups were comppared in terms of pre- and post-operative mean hemoglobin, creatinine, nephrostomy time, nephrostomy tube diameter, operative time, and fluoroscope time. $\boldsymbol{R e}$ sults: Mean operative time, preoperative hemoglobin and creatinine values were similar in all groups. Postoperative mean hemoglobin level was significantly lower and postoperative mean creatinine level was significantly higher in patients who were treated with a larger Amplatz sheath when compared to a smaller size $(p<0.05)$. It was observed that nephrostomy time and nephrostomy tube size significantly increased as the Amplatz sheath size increased. Seven patients presented with postoperative infection $(1,2,1,0$ and 3 patients in Group I, II, III, IV, and V respectively), 13 patients presented with bleeding requiring blood transfusion $(2,4$, and 7 patients in Group III, IV, and V respectively), and residu-
\end{abstract}

\section{KARGER}

Fax +4161306 1234

E-Mail karger@karger.ch

www.karger.com
(C) 2013 S. Karger AG, Basel

1015-9770/13/0073-0127\$38.00/0

Accessible online at:

www.karger.com/cur al stone was observed in 9 patients $(5,2,0,1$, and 1 patients in Group I, II, III, IV, and V respectively). Conclusion: Although the use of a larger Amplatz sheath for larger stones seems to be suitable, this is not the case for smaller stones. For smaller stones, a smaller Amplatz sheath size would be useful to decrease the bleeding and renal impairment rates.

Copyright @ 2013 S. Karger AG, Basel

\section{Introduction}

Percutaneous nephrolithotomy (PCNL) has become a standard procedure in the surgical treatment of larger renal or proximal ureteral stones [1-3]. Since the procedure was first described, several efforts have been made to improve the outcome and decrease the complication rates [2-4]. Although the procedure has various advances, some issues associated with the PCNL remain a matter of debate [3].

Recently there have been several reports in the literature investigating the effect of nephrostomy tube size on the success, bleeding, renal function impairment and postoperative urinary leak rates [1-3]. In addition there have been many trials that compared the nephrostomy 
drainage with no nephrostomy (tubeless) drainage following PCNL $[1-3,5,6]$. In most of the previous studies a 26 to 30 Fr Amplatz sheath was positioned into the renal collecting system $[1,3]$. None of these reports included any data presenting the effect of Amplatz sheath size on surgical outcomes and perioperative findings.

In this recent study we retrospectively evaluated the effect of Amplatz sheath size used in PCNL on postoperative outcomes, bleeding, and renal impairment. We also compared nephrostomy tube size and duration, operative time and fluoroscope time. To the best of our knowledge, this study represents the first trial comparing Amplatz sheath size in terms of perioperative findings of patients undergoing PCNL.

\section{Materials and Methods}

The records of 110 patients (66 males and 44 females) who underwent uneventful PCNL by 2 different surgeons between November 2011 and October 2012 were retrospectively evaluated. The patients were divided into 5 groups based on the Amplatz sheath size $(22,24,26,28$ and $30 \mathrm{Fr})$ used in the PCNL procedure. Patients with complicated procedures, multiple subcostal percutaneous tracts, abnormal preoperative renal functions, presence of previous surgery on the ipsilateral urinary tract, pyonephrosis and intraoperative complications including extreme blood loss and perforation were excluded from the study.

All patients were operated on in the prone position through a single percutaneous access following retrograde ureteral catheterization under general anesthesia. Initial percutaneous renal access to either the lower or the middle calyx was performed under radiological assistance using X-ray in combination with retrograde intra-renal contrast injection. Once access was obtained, a Sensor guidewire (Boston Scientific ${ }^{\circledR}$ ) was inserted and maneuvered toward the ureter. A 22 to $30 \mathrm{Fr}$ Amplatz sheath was positioned in the renal collecting system following progressive dilation of the tract using serial dilators under fluoroscopic control. The stones were disintegrated with pneumatic lithotripsy and removed using a foreign body grasper. The nephrostomy tube was introduced under fluoroscopic control. The nephrostomy tube was closed following the procedure for hemostasis and re-opened at the postoperative 2nd hour unless the patient experienced pain. The nephrostomy tube was removed when the urine become clear and all patients were discharged 12 hours following nephrostomy tube removal if there is no urinary leak. We regarded patients with residual stones $\leq 4 \mathrm{~mm}$ as stone free.

Five groups were retrospectively compared in terms of pre- and post-operative hemoglobin and renal function, mean nephrostomy time, mean nephrostomy tube diameter, mean operative time, and mean fluoroscope time.

Statistical analyses were performed using SPSS version 15.0. Regression analyses were used to analyze continuous variables and categorical variables were analyzed using the chi-square test. All findings were represented as mean \pm SD. A p value of $<0.05$ was accepted as statistically significant.

\section{Results}

Mean age of the patients was $44.75 \pm 13.79$ years old (range 22-72 years) and mean stone diameter was $30.35 \pm 9.68 \mathrm{~mm}$ (range 10-55 mm). Mean operative and fluoroscope time were $109.81 \pm 42.43$ minutes (range 40-240 minutes) and 12.83 \pm 9.61 minutes (range 3-35 minutes) respectively. Table 1 includes patients' characteristics and stones' properties. There was no statistical difference between the 5 groups in terms of age, male to female ratio, mean maximum stone diameter, number of stones, and side effects.

Results are summarized in table 2 and fig. 1. Mean operative time, mean preoperative hemoglobin and creatinine values were similar in all 5 groups. There was a significant difference between groups in terms of mean fluoroscope time, postoperative hemoglobin and creatinine values, nephrostomy time and nephrostomy tube size (p $<0.05$ ). The postoperative mean hemoglobin level was significantly lower and the postoperative mean creatinine level was significantly higher in patients who were treated with a larger Amplatz sheath when compared to a smaller size $(\mathrm{p}<0.05)$. It was observed that nephrostomy time and nephrostomy tube size significantly increased as the Amplatz sheath size increased $(<0.05)$.

Seven patients presented with postoperative infection (Clavien grade 1) (1, 2, 1, 0 and 3 patients in Group I, II, III, IV, and V respectively), 13 patients presented with bleeding requiring blood transfusion (Clavien grade 2) ( 2,4 , and 7 patients in Group III, IV, and V respectively), residual stone was observed in 9 patients $(5,2,0,1$, and 1 patients in Group I, II, III, IV, and V respectively), and 8 patients had antegrade placement of a 6 Fr double-J stent $(4,2,0,0$, and 2 patients in Group I, II, III, IV, and $\mathrm{V}$ respectively). None of the patients presented with prolonged postoperative urinary leak and no patient required any ancillary procedure.

\section{Discussion}

Morbidity associated with the open surgery for larger renal and proximal ureteral calculi has significantly decreased with the use of PCNL [1]. Although PCNL is a well-defined procedure, the surgical technique is still changing since most clinicians are trying to optimize the outcomes and minimize the complications and patients' discomfort related with the procedure [2, 3]. Previous studies mainly discussed PCNL exit strategy including nephrostomy drainage versus no nephrostomy drainage (tubeless) and nephrostomy tube type and size if used 
Table 1. Demographic characteristics of patients

\begin{tabular}{|c|c|c|c|c|c|}
\hline & $22 \mathrm{Fr}$ & $24 \mathrm{Fr}$ & $26 \mathrm{Fr}$ & $28 \mathrm{Fr}$ & $30 \mathrm{Fr}$ \\
\hline Patients, $\mathrm{n}$ & 15 & 19 & 26 & 18 & 32 \\
\hline Age, years & $45.6 \pm 12.52(26-71)$ & $45.94 \pm 14.69(24-72)$ & $46.19 \pm 12.24(25-71)$ & $41.88 \pm 16.53(22-69)$ & $45.37 \pm 13.80(24-72)$ \\
\hline Male:female & $9: 6$ & $11: 8$ & $17: 9$ & $8: 10$ & $21: 11$ \\
\hline Right: left side & $8: 7$ & $10: 9$ & $18: 8$ & $9: 9$ & $15: 17$ \\
\hline Max stone diameter, $\mathrm{mm}$ & $34.36 \pm 10.41(10-45)$ & $37.47 \pm 10.35(17-53)$ & $37.88 \pm 14.14(10-55)$ & $36.49 \pm 11.33(25-50)$ & $37.53 \pm 12.23(30-55)$ \\
\hline Multiple stones, $\mathrm{n}$ & 7 & 9 & 11 & 10 & 15 \\
\hline Staghorn stone, $\mathrm{n}$ & 3 & 7 & 8 & 5 & 13 \\
\hline
\end{tabular}

Table 2. Perioperative findings of patients

\begin{tabular}{|c|c|c|c|c|c|c|}
\hline & $22 \mathrm{Fr}$ & $24 \mathrm{Fr}$ & $26 \mathrm{Fr}$ & $28 \mathrm{Fr}$ & $30 \mathrm{Fr}$ & $\mathrm{p}$ \\
\hline Operative time, minute & $\begin{array}{l}102.8 \pm 30.0 \\
(55-126)\end{array}$ & $\begin{array}{l}105.5 \pm 39.5 \\
(75-210)\end{array}$ & $\begin{array}{l}103.7 \pm 40.5 \\
(40-115)\end{array}$ & $\begin{array}{l}110.6 \pm 45.3 \\
(70-240)\end{array}$ & $\begin{array}{l}108.1 \pm 48.6 \\
(65-220)\end{array}$ & $>0.05$ \\
\hline Preoperative $\mathrm{Hb}, \mathrm{g} / \mathrm{dl}$ & $\begin{array}{l}14.3 \pm 1.5 \\
(11.6-17)\end{array}$ & $\begin{array}{l}13.9 \pm 1.8 \\
(9.10-17)\end{array}$ & $\begin{array}{l}14.7 \pm 1.4 \\
(11.7-17)\end{array}$ & $\begin{array}{l}14.4 \pm 1,4 \\
(11.6-16.9)\end{array}$ & $\begin{array}{l}14.2 \pm 1.6 \\
(9.10-17)\end{array}$ & $>0.05$ \\
\hline Preoperative creatinine, $\mathrm{mg} / \mathrm{dl}$ & $\begin{array}{l}0.9 \pm 0.3 \\
(0.4-1.56)\end{array}$ & $\begin{array}{l}0.8 \pm 1.1 \\
(0.57-1.1)\end{array}$ & $\begin{array}{l}0.9 \pm 0.18 \\
(0.58-1.37)\end{array}$ & $\begin{array}{l}0.9 \pm 0.27 \\
(0.48-1.56)\end{array}$ & $\begin{array}{l}0.85 \pm 0.2 \\
(0.4-1.29)\end{array}$ & $>0.05$ \\
\hline Postoperative creatinine, $\mathrm{mg} / \mathrm{dl}$ & $\begin{array}{l}0.9 \pm 0.24 \\
(0.5-1.3)\end{array}$ & $\begin{array}{l}0.98 \pm 0.38 \\
(0.64-1.7)\end{array}$ & $\begin{array}{l}1.05 \pm 0.28 \\
(0.81-1.91)\end{array}$ & $\begin{array}{l}1.26 \pm 0.28 \\
(0.60-1.96)\end{array}$ & $\begin{array}{l}1.56 \pm 0.43 \\
(0.9-2.43)\end{array}$ & $<0.05$ \\
\hline Nephrostomy duration, day & $\begin{array}{l}1 \pm 0.7 \\
(1-4)\end{array}$ & $\begin{array}{l}1.47 \pm 1.02 \\
(1-5)\end{array}$ & $\begin{array}{l}2.03 \pm 1.66 \\
(1-7)\end{array}$ & $\begin{array}{l}2.77 \pm 0.98 \\
(2-6)\end{array}$ & $\begin{array}{l}3.86 \pm 1.11 \\
(3-7)\end{array}$ & $<0.05$ \\
\hline Nephrostomy diameter, $\mathrm{mm}$ & $\begin{array}{l}12.4 \pm 1.35 \\
(10-14)\end{array}$ & $\begin{array}{l}13.26 \pm 1.19 \\
(10-14)\end{array}$ & $\begin{array}{l}14.46 \pm 2.13 \\
(10-20)\end{array}$ & $\begin{array}{l}15.33 \pm 2.37 \\
(12-20)\end{array}$ & $\begin{array}{l}16.06 \pm 2.71 \\
(12-20)\end{array}$ & $<0.05$ \\
\hline
\end{tabular}

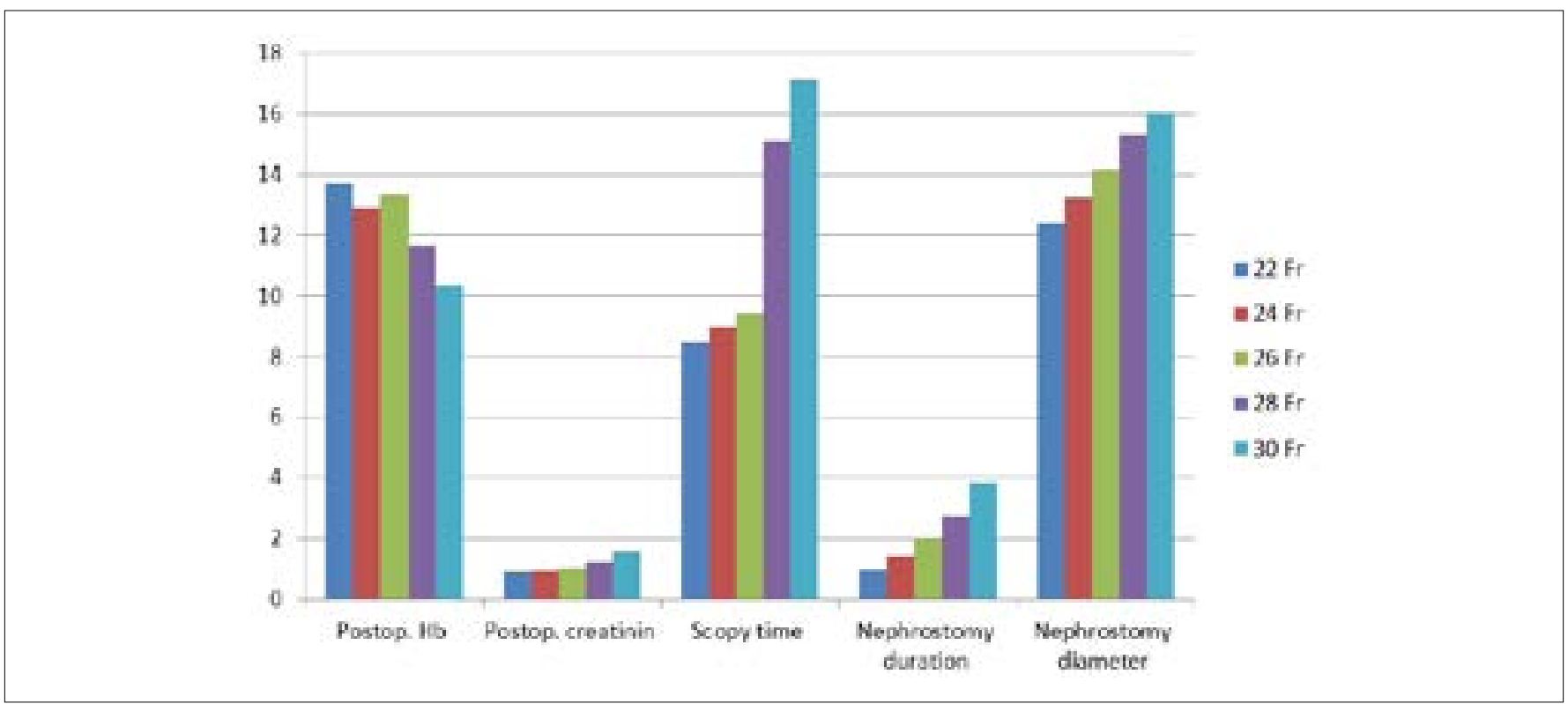

Fig. 1. Mean fluoroscope time, nephrostomy duration, nephrostomy tube diameter, postoperative hemoglobin and creatinine values were significantly different among groups. 
$[1-3,7-10]$. There has been increasing evidence that the drainage method used in PCNL may significantly affect the outcomes and complications including hospital stay, patients' discomfort, bleeding, prolonged urinary leak, and renal impairment $[1,2]$.

Recently tubeless PCNL has been advocated by various trials in short and uncomplicated cases with minimal bleeding, fewer complications, and reduced hospital stay [1,3,9-13]. Desai et al [1] prospectively compared postoperative outcomes among tubeless, conventional large bore and small bore nephrostomy drainage. They concluded that tubeless PCNL is associated with the least postoperative pain, urinary leakage, and hospital stay. In contrast several studies demonstrated that nephrostomy tube placement is mandatory providing hemostatic tamponade for the percutaneous renal tract, continuing access to the renal collecting system if a second look procedure is required and avoiding urinary extravasation $[2,3]$. There are conflicting findings associated with the type and size of the nephrostomy tube used to drain the renal collecting system following PCNL [2].

In a previous study 3 different nephrostomy tube types including 24 Fr re-entry tube, 8 Fr pigtail catheter, and double $\mathbf{J}$ stent plus 18 Fr Councill-tip catheter were compared [14]. The authors noted no statistical difference in terms of pain scores, hematocrit change and hospital stay. In a recent study, the effect of nephrostomy tube size (22 Fr vs. 12 Fr) on perioperative outcomes of PCNL was investigated [3]. This study showed that a small bore nephrostomy tube can safely be used instead of a larger size tube following uncomplicated PCNL procedure since the size of the nephrostomy tube does not affect blood loss and hospital stay. In a similar study the authors explored the relationship between nephrostomy tube size and results of PCNL [2]. The authors concluded that a large bore nephrostomy tube reduces bleeding and overall complication rate. In a different study the authors concluded that in PCNL, factors that are associated with bleeding/transfusion include sheath size, operating time, stone load, and caseload [15].

Previous studies have not discussed the potential impact of Amplatz sheath size on surgical outcomes of the PCNL procedure. To the best of our knowledge this recent study represents the first trial investigating the effect of Amplatz sheath size on surgical outcomes and perioperative findings of PCNL. We tried to evaluate the effect of Amplatz sheath size used in PCNL on postoperative outcomes, bleeding, and renal impairment. We also compared nephrostomy tube size and duration, operative time, and fluoroscope time.
Postoperative mean hemoglobin level was significantly lower and postoperative mean creatinine level was significantly higher in the patients who were treated with a larger Amplatz sheath when compared to a smaller size. We think that although PCNL is a minimally invasive procedure to the skin, the technique is still invasive for the kidney. The findings of the recent study proved that the use of a small size Amplatz sheath is less harmful to the kidney resulting in less bleeding and less renal impairment. Although we have not objectively evaluated the postoperative pain status of the patients, it was observed that the use of a small size Amplatz sheath decreased the postoperative patient discomfort. However, further studies investigating postoperative pain with valid pain scoring systems are needed.

In contrast to the results of the study reported by Cormio et al. [2], the present findings showed that nephrostomy tube size and bleeding significantly increased as the Amplatz sheath size increased. We think that the Amplatz sheath size is more crucial than the size of the nephrostomy tube used to drain the renal collecting system in terms of bleeding and renal impairment. Although the impact of percutaneous tract dilatation in terms of intraoperative bleeding was not prospectively evaluated in the recent study, in our clinical experience we observed more intraoperative bleeding following $24 \mathrm{Fr}$ or larger dilatators. A recent study advocated that the size of the nephrostomy tube does not affect blood loss and hospital stay [3]. In contrast, the present findings showed that the use of a small size Amplatz sheath significantly decreased the nephrostomy tube size, bleeding, nephrostomy time and hospital stay.

This recent study has some limitations including the retrospective design which might introduce some selection bias. When our PCNL data were retrospectively reviewed, it was observed that a smaller Amplatz sheath was preferred for smaller stones and a larger Amplatz sheath for complex and larger stones. It could be argued that more difficult stones or geometries might potentially mandate a larger Amplatz size. Although generally a 30 Fr Amplatz sheath is preferred in PCNL regardless of the stone diameter, it was hypothesized that using a small sized Amplatz sheath for smaller stones, would potentially decrease complication and bleeding rates. It was thought that although using a larger Amplatz sheath for larger stones seems to be suitable, this is not true for smaller stones. Further randomized prospective studies including a matched group of staghorn stones treated with smaller sheaths would more objectively support the findings of the present study. Our findings demonstrated 
that the stone-free rate is negatively related to the Amplatz sheath size. This might possibly be because only the pneumatic lithotripsy device was used for fragmentation of stones. We suppose that our stone-free rates would potentially be better if we could use both pneumatic and ultrasonic lithotripsy devices. Different Amplatz sheath sizes were compared and a nephrostomy tube was inserted in all patients. Further prospective and randomized studies including different sized nephrostomy tube drainage and no nephrostomy drainage (tubeless) groups would probably more objectively demonstrate the effect of Amplatz sheath size on perioperative outcomes.

\section{Conclusion}

Although the use of a large bore Amplatz sheath in PCNL procedure for larger stones seems to be suitable, this is not the case for smaller stones. For smaller stones a smaller Amplatz sheath size would be useful to reduce bleeding, renal impairment rates, and patients' postoperative discomfort.

\section{References}

1 Desai MR, Kukreja RA, Desai MM, Mhaskar SS, Wani KA, Patel SH, Bapat SD: A prospective randomized comparison of type of nephrostomy drainage following percutaneous nephrostolithotomy: large bore versus small bore versus tubeless. J Urol 2004;172: 565-567.

2 Cormio L, Preminger G, Saussine C, Buchholz NP, Zhang X, Walfridsson H, Gross AJ, de la Rosette J: Nephrostomy in percutaneous nephrolithotomy (PCNL): does nephrostomy tube size matter? Results from the Global PCNL Study from the Clinical Research Office Endourology Society. World J Urol 2013; 31:1563-1568.

3 De Sio M, Autorino R, Quattrone C, Giugliano F, Balsamo R, D'Armiento M: Choosing the nephrostomy size after percutaneous nephrolithotomy. World J Urol 2011;29:707711.

4 Fernstrom I, Johansson B: Percutaneous pyelolithotomy. A new extraction technique. Scand J Urol Nephrol 1976;10:257-259.

5 Borges CF, Fregonesi A, Silva D, Sasse AD: Systematic review and meta-analysis of nephrostomy placement versus tubeless percutaneous nephrolithotomy. J Endourol 2010; 24:1739-1746.
6 Ni S, Qiyin C, Tao W, Liu L, Jiang H, Hu H, Han R, Wang C: Tubeless percutaneous nephrolithotomy is associated with less pain and shorter hospitalization compared with standard or small bore drainage: a meta-analysis of randomized, controlled trials. Urology 2011;77:1293-1298.

7 Bellman GC, Davidoff R, Candela J, Gerspach J, Kurtz S, Stout L: Tubeless percutaneous renal surgery. J Urol 1997;157:15781582.

8 Lojanapiwat B, Soonthornphan S, Wudhikarn S: Tubeless percutaneous nephrolithotomy in selected patients. J Endourol 2001;15:711713.

9 Shah HN, Sodha HS, Khandkar AA, Kharodawala S, Hegde SS, Bansal MB: A randomized trial evaluating type of nephrostomy drainage after percutaneous nephrolithotomy: small bore v tubeless. J Endourol 2008;22:1433-1439.

10 Crook TJ, Lockyer CR, Keoghane SR, Walmsley BH: A randomized controlled trial of nephrostomy placement versus tubeless percutaneous nephrolithotomy. J Urol 2008; 180:612-614.
11 de Cogain MR, Krambeck AE: Advances in tubeless percutaneous nephrolithotomy and patient selection: an update. Curr Urol Rep 2013;14:130-137.

12 Crook TJ, Lockyer CR, Keoghane SR, Walmsley BH: Totally tubeless percutaneous nephrolithotomy. J Endourol 2008;22:267271.

13 Limb J, Bellman GC: Tubeless percutaneous renal surgery: review of first 112 patients. Urology 2002;59:527-531.

14 Marcovich R, Jacobson AI, Singh J, Shah D, El-Hakim A, Lee BR, Smith AD: No panacea for drainage after percutaneous nephrolithotomy. J Endourol 2004;18:743-747.

15 Yamaguchi A, Skolarikos A, Buchholz NP, Chomón GB, Grasso M, Saba P, Nakada S, de la Rosette J: Operating times and bleeding complications in percutaneous nephrolithotomy: a comparison of tract dilation methods in 5,537 patients in the Clinical Research Office of the Endourological Society Percutaneous Nephrolithotomy Global Study. J Endourol 2011;25:933-939. 